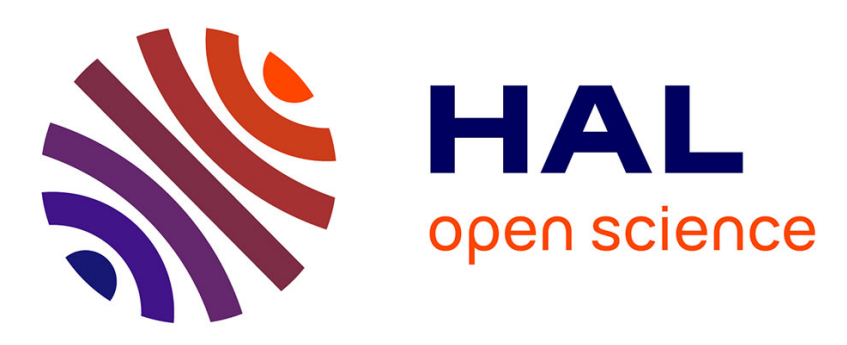

\title{
Magnetooptical Kerr Spectra in Sputtered Strontium Ferrite Films
}

\author{
S. Visnovský, M. Nývlt, R. Krishnan, B. Ramamurthy Acharya, S. Prasad, N. \\ Venkatramani
}

\section{- To cite this version:}

S. Visnovský, M. Nývlt, R. Krishnan, B. Ramamurthy Acharya, S. Prasad, et al.. Magnetooptical Kerr Spectra in Sputtered Strontium Ferrite Films. Journal de Physique IV Proceedings, 1997, 07 (C1), pp.C1-721-C1-722. 10.1051/jp4:19971294 . jpa-00255059

\section{HAL Id: jpa-00255059 https://hal.science/jpa-00255059}

Submitted on 1 Jan 1997

HAL is a multi-disciplinary open access archive for the deposit and dissemination of scientific research documents, whether they are published or not. The documents may come from teaching and research institutions in France or abroad, or from public or private research centers.
L'archive ouverte pluridisciplinaire HAL, est destinée au dépôt et à la diffusion de documents scientifiques de niveau recherche, publiés ou non, émanant des établissements d'enseignement et de recherche français ou étrangers, des laboratoires publics ou privés. 


\title{
Magnetooptical Kerr Spectra in Sputtered Strontium Ferrite Films
}

\author{
S. Visnovský, M. Nývlt, R. Krishnan*, B. Ramamurthy Acharya**, S. Prasad** and N. Venkatramani** \\ Institute of Physics, Charles University, , Ke Karlovu 5, CZ-12116 Prague 2 \\ * Laboratoire de Magnétisme et d'Optique, URA 1532, CNRS, 92195 Meudon, France \\ ** Department of Physics, Indian Institute of Technology, Bombay 400076, India
}

\begin{abstract}
Magnetooptic (MO) polar Kerr effect spectra and MO hysteresis loops of $\mathrm{SrFe}_{12} \mathrm{O}_{19}$ hexagonal ferrite films are presented. The films were prepared by $f$ sputtering and subsequently annealed at 800 or $900^{\circ} \mathrm{C}$ in $O_{2} / A r$. The crystallographic orientation with the $c$-axis perpendicular to the film plane was checked using XRD. The films display perpendicular magnetic anisotropy and rectangular hysteresis loops with a remanence ratio close to one. At low photon energies below the absorption edge of $\mathrm{SrFe}_{12} \mathrm{O}_{19}$ at $2.5 \mathrm{eV}$ MO spectra are affected by the radiation penetration into the film and the quartz substrate. Above this energy they display the features typical for bulk $\mathrm{SrFe}_{12} \mathrm{O}_{19}$ crystals. The coercive field, structure of the MO spectra and the maguitude of the prominent peak in the spectra near $4.5 \mathrm{eV}$ can be correlated with the structural quality of the films. Consequently, the magnetooptics can serve as a diagnostics tool for these films.
\end{abstract}

Hexagonal ferrite films with perpendicular magnetic anisotropy prepared by $r f$ sputtering or laser ablation received attention as a new magnetic recording material [1-6]. Magnetooptic (MO) magnetometry and spectroscopy provide cheap and rapid tool for the diagnostics of these films. The paper deals with MO complex polar Kerr effect in sputtered $S r$ hexagonal ferrite films. The MO experiments were carried out at nearly normal incidence. In this arrangement the effect of the uniaxial optical anisotropy in the $\mathrm{SrFe}_{12} \mathrm{O}_{19}$ films was minimized. The $\mathrm{SrFe}_{12} \mathrm{O}_{19}$ films with thicknesses ranging from 200 to $550 \mathrm{~nm}$ were deposited on quartz substrates by sputtering keeping the $r f$ power at 96 or $228 \mathrm{~W}$. No substrate heating was done. The subsequent annealing was performed in controlled heating and cooling steps in $\mathrm{O}_{2} / \mathrm{Ar}$ gas with either 1.5 or $15 \%$ of $\mathrm{O}_{2}$. XRD was employed to check for the crystallographic orientation. Prior the spectroscopic experiment, fixed wavelength polar Kerr loops were taken. The observed coercive field ranged between 3 and $6 \mathrm{kOe}$. From the series of studied samples films we shall focus on two $\mathrm{SrFe}_{12} \mathrm{O}_{19}$ films $238 \mathrm{~nm}$ thick sputtered at $r f$ power of $96 \mathrm{~W}$ prepared using $\mathrm{Ar}$ and $1.5 \%$ of $\mathrm{O}_{2}$ and annealed at 800 and $900^{\circ} \mathrm{C}$, respectively. XRD of the former sample displayed only (006), (008) and (0014) lines showing that it is oriented with $c$-axis perpendicular to the plane of the film. The film annealed at $900^{\circ} \mathrm{C}$ displayed a low intensity (107) line in addition. The reason for the $c$-axis orientation is not clear at present. Such orientation has also been observed in films obtained by pulsed laser deposition [5].

The MO polar Kert spectra measured in the photon energy range between 1.5 and $5.2 \mathrm{eV}$ are given in Fig. 1 . The MO hysteresis loops of these films are also shown. Note that the coercivity of the film annealed at $800^{\circ} \mathrm{C}$ is $3 \mathrm{kOe}$ while that one annealed at $900^{\circ} \mathrm{C}$ is $5 \mathrm{kOe}$. Because of low film thicknesses $(200$ to $350 \mathrm{~nm}$ ) the MO spectra at photon energies below the absorption edge of hexagonal ferrites $(2.5 \mathrm{eV}$ ) are affected by the reflections at the film-substrate and substrate-ambient interfaces. In this way besides the MO Kerr effect at air-ferrite interface we have to account for the MO propagation in the ferrite film, MO contribution from ferrite-substrate interface and non-zero Verdet constant of the $1 \mathrm{~mm}$ thick quartz substrate. This last contribution, which little affects the observed ellipticity, could be minimized. To estimate it the rotation was measured in the remanent state at a zero applied field and the use was made of the experimentally determined remanence ratio which is close to one. The results were then compared with those in the field of 1 Tesla. The substrate contribution was significant in the region below $2.5 \mathrm{eV}$ only and manifested itself by a positive rotation shift less than $0.03 \mathrm{deg}$.

To evaluate the effect of the propagation in the magnetic film we therefore neglect the effect of final thickness of the quartz substrate, i.e., we assume a zero reflection coefficient at the substrate-sample holder interface, and obtain an expression for the complex MO effect $\chi_{r}=\theta_{r}+\mathrm{i} \varepsilon_{r}$ (where $\theta_{r}$ is the rotation and $\varepsilon_{r}$ the ellipticity) in this magnetic film-substrate system [7]

$$
\chi_{r}=\chi_{r}^{(01)} r_{01}\left[\left(1+r_{12}^{2} \mathrm{e}^{-2 \mathrm{i} \beta}\right)\left(1-\mathrm{e}^{-2 \mathrm{i} \beta}\right)+4 \mathrm{i} \beta \mathrm{e}^{-2 \mathrm{i} \beta} r_{12}\right] /\left[\left(1+r_{01} r_{12} \mathrm{e}^{-2 \mathrm{i} \beta}\right)\left(r_{01}+r_{12} \mathrm{e}^{-2 \mathrm{i} \beta}\right)\right]
$$

The reflection coefficients at air-film and film-substrate interfaces are respectively $r_{01}$ and $r_{12}$. We have denoted the MO Kerr effect of a single air-magnetic film interface as $\chi_{r}^{(01)}$

$$
\chi_{r}^{(01)}=\varepsilon_{x y}^{(1)} /\left[\left(\varepsilon_{x x}^{(1)}\right)^{1 / 2}\left(\varepsilon_{x x}^{(1)}-1\right)\right]
$$

where $\varepsilon_{x y}{ }^{(1)}$ and $\varepsilon_{x x}{ }^{(1)}$ are the off-diagonal and diagonal MO permittivity tensor elements of the magnetic film medium, respectively. The contribution of the propagation effect in the film and that of the reflections at film substrate interface will be negligible when the multiplication factor at $\chi_{r}^{(01)}$ in (1) becomes close to one. In the case of our film this means that the 

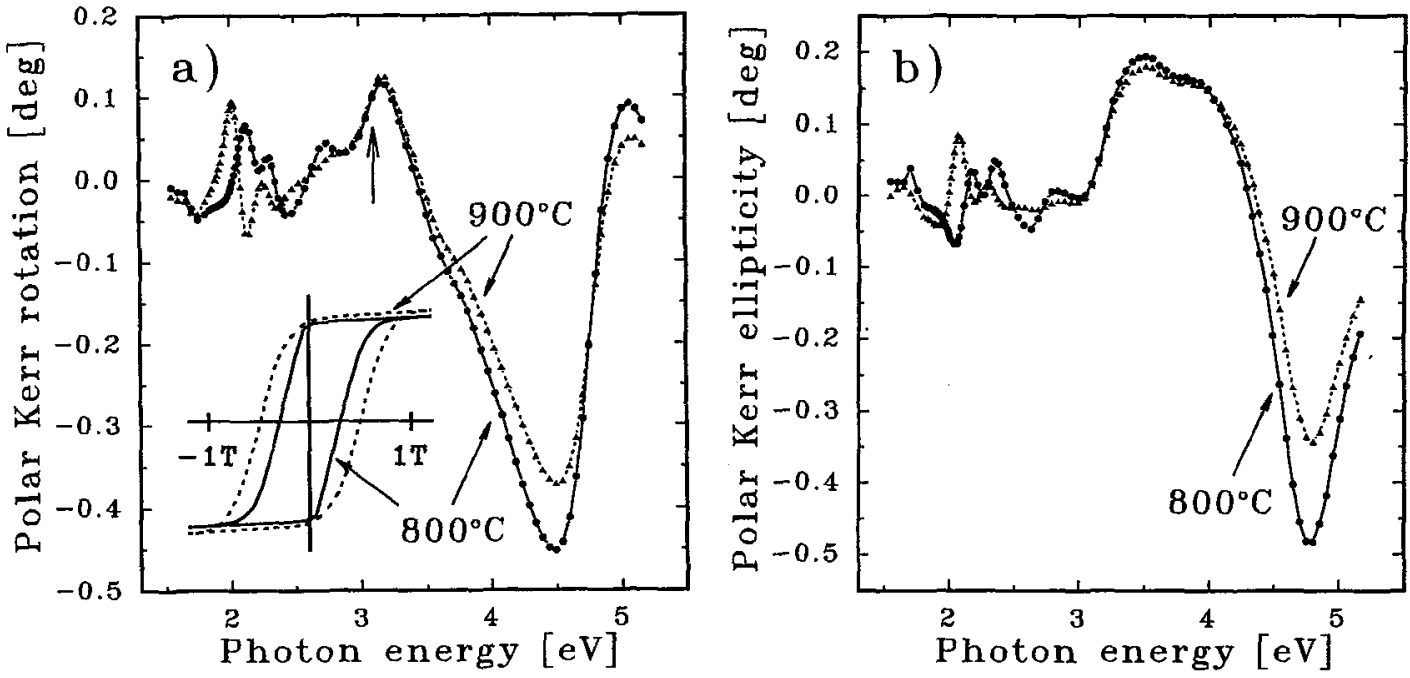

Fig. 1. Magnetooptic polar Kerr rotation (a) and ellipticity (b) spectra of $\mathrm{Sr} F e_{12} \mathrm{O}_{19}$ films $238 \mathrm{~nm}$ thick sputtered at $v f$ power of $96 \mathrm{~W}$ using $\mathrm{Ar}$ and $1.5 \%$ of $\mathrm{O}_{2}$ and subsequently annealed at 800 and $900^{\circ} \mathrm{C}$, respectively. The applied magnetic field was 1 esla. The inset shows the magnetooptic polar Kerr hysteresis loops measured at a wavelength $400 \mathrm{~mm}$.

absorption coefficient should be higher than $10^{3} \mathrm{~cm}^{-1}$ i.e. $\left|\mathrm{e}^{-2 \mathrm{i} \beta}\right|<<1$, where $\beta=(\omega / c) N^{(1)} t^{(1)}$; here $(\omega / c)$ denotes the magnitude of the radiation wavevector in a vacuum, $N^{(1)}=\left(\varepsilon_{x x}{ }^{(1)}\right)^{1 / 2}$ and $t^{(1)}$ is the thickness of the magnetic film.

As expected the optical transmission measurements of the $S r F e_{12} O_{19}$ films confirmed that the condition $\chi_{r} \approx \chi_{r}^{(01)}$ is met at the photon energies above $2.5 \mathrm{eV}$. Above this energy the spectra display the shape similar to that observed in bulk crystals $[5,8-10]$. This is consistent with the good quality of the films confirmed by XRD.

The sample annealed at $800^{\circ} \mathrm{C}$ shows a better resolved structure at low photon energies (between 2.5 and $3 \mathrm{eV}$ ) and a higher magnitude of the negative rotation peak centered near $4.5 \mathrm{eV}$. These trends seem to be general: a less resolved low energy structure and a reduced amplitude of the peak near $4.5 \mathrm{eV}$ (as much as $50 \%$ ) are typical for the films of lower degree of perfection. This suggests that the MO Kerr spectroscopy may be employed here as a rapid and cheap diagnostics tool.

\section{Acknowledgments}

This work has been partially supported by Grant Agency FRVŠ of Czech republic (FR720, FR 795, FR 1002), Grant Agency of the Charles University (GAUK 165/95) and Konstruktis Praha, Inc.

\section{References}

[1] H. Machida, F. Ohmi, Y. Sawada, Y. Kaneko, A. Watada and H. Nakamura, J. Magn. Magn. Mater. 54 (1986) 1399.

[2] N. Matsushita and M. Nace, IEEE Trans. Magn. 29 (1993) 4089.

[3] Y. Hoshi, D. E. Speliotis and J. H. Judy, in Ferrites: Proceedings of Sixth International Conference on Ferrites, Tokyo, 1992,440 .

[4] Z. Šimša, R. Gerber, R. Atkinson and P. Papakonstantinou, in Ferrites: Proceedings of Sixth International Conference on Ferrites, Tokyo, 1992, 730.

[5] R. Atkinson, P. Papakonstantinou, I. W. Salter, R. Gerber, J. Magn. Magn. Mat. 138 (1994) 222.

[6] B. Ramamurthy Acharya, N. Venkatramani, Shiva Prasad, S.N. Shringi, R. Krishnan, M. Tessier and Y. Dumond, IEEE Trans. on Mag. 29, 3370 (1993).

[7] Š. Višňovký, Czech. J. Phys. B 36 (1986) 625, 834.

[8] K. Shono, M. Gomi, M. Abe, Jap. J. Appl. Phys. 21, (1982) 1451.

[9] Z. Šimša, P. Široký, F. Lukeš, E. Schmidt, phys. stat. sol. (b) 96 (1979) 137.

[10] Š. Višňovský, P. Siroký and R. Krishnan, Czech. J. Phys. B 36 (1986) 1434. 